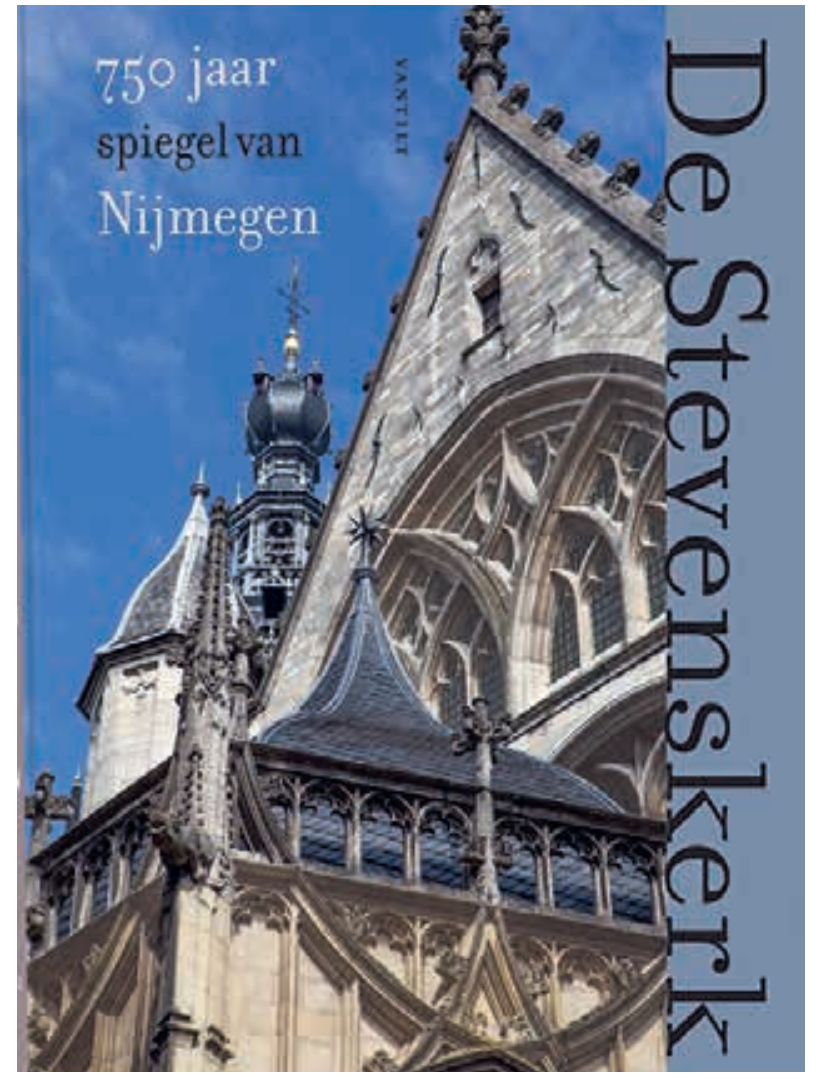

In 1254 stichtte graaf Otto II van Gelre een nieuwe parochiekerk voor Nijmegen. De oude kerk aan de oostzijde van de Valkhofburcht moest plaatsmaken voor nieuwe verdedigingswerken. Zeven jaar eerder had de graaf de stad, inclusief burcht, verworven als onderpand voor een kapitale lening aan rooms-koning Willem van Holland. Omdat deze nooit werd afgelost, kwam Nijmegen aan Gelre. De nieuwe kerk verrees op de Hundisberg, ongeveer vijfhonderd meter ten westen van het Valkhof. Sinds die tijd ontwikkelde de Stevenskerk zich als hoofdkerk van de stad. Dat gegeven vormt het overkoepelende thema voor De Stevenskerk. 750 jaar spiegel van Nijmegen, geschreven in opdracht van de Stichting Stevenskerk en de gemeente Nijmegen.

Aanleiding voor deze uitgave waren in 2013-2015 uitgevoerde restauratiewerkzaamheden. Deze maakten grondig bouwhistorisch onderzoek op de steiger mogelijk. Het was ook tijd voor een nieuwe studie over deze bijzondere kerk; naast een reeks kleinere deelstudies waren er alleen de monografie van gemeentearchivaris H.D.J. van Schevichaven uit 1900 en de Historische bijdragen bij gelegenheid van de voltooiing der restauratie uit 1969.

Elf specialisten leverden de teksten voor dit nieuwe boek. De betreurde Jan Kuys tekende voor de hoofdstukken over de vroegste geschiedenis van de Nijmeegse parochiekerk, de stichting van het kapittel, de turbulente ontwikkelingen in de zestiende eeuw en de betekenis van de heilige Stefanus voor Nijmegen.
HETTIE PETERSE, ELSBETH ROOKER, ROB CAMPS EN KAREL EMMENS (RED.)

\section{DE STEVENSKERK}

\section{JARR SPIEGEL VAN NIJMEGEN}

Nijmegen (Vantilt) 2017, 320 pp., ills. in kleur, ISBN 978946004345 1, € 29,95
Karel Emmens zorgde voor verreweg de grootste bijdrage in de vorm van een uitgebreide analyse van de middeleeuwse bouwgeschiedenis. Elizabeth den Hartog analyseerde de bouwsculptuur, terwijl Paul le Blanc de middeleeuwse schilderingen voor zijn rekening nam. Gerard Lemmens en Jörg Soentgerath onderzochten het graf van Catharina van Bourbon. Voor de periode vanaf de Reductie van Nijmegen in 1591 belichtten Lemmens en Anton van de Sande respectievelijk de bouw- en interieurgeschiedenis en het gebruik van de kerk. De drie orgels van de kerk werden onder de loep genomen door Joost Langeveld. Ronald Glaudemans schreef het gedeelte over de vroegtwintigsteeeuwse restauratiegeschiedenis en de verwoesting en wederopbouw na de Tweede Wereldoorlog en Mayke Haaksma en Louis Gerdessen blikken terug op de recente restauratie van kerk en toren.

Een bespreking van een boek met zoveel onderwerpen en auteurs overstijgt de ruimte die in dit kader beschikbaar is. Deze recensie concentreert zich daarom op de middeleeuwse periode, die het grootste deel van het boek beslaat. De andere bijdragen in dit boek zijn echter alleszins de moeite waard. Ze dragen wezenlijk bij aan een beter begrip van de Nijmeegse hoofdkerk zoals wij die kennen. Zeker voor het aanzien van het kerkinterieur zijn de post-reformatorische ontwikkelingen bepalend geweest.

Puttend uit jarenlang bouwhistorisch onderzoek beschrijft Karel Emmens op overtuigende wijze stap voor stap de bouwgeschiedenis. Talrijke tekeningen, sche- 
ma's en illustraties ondersteunen zijn betoog. Dankzij de steeds onvoltooide projecten zijn van de oudere bouwfases substantiële delen bewaard, wat bouwhistorisch onderzoek aan deze kerk bijzonder dankbaar maakt. Daarbij betrekt Emmens ook de schriftelijke bronnen. Hoewel het middeleeuwse archief van de kerk grotendeels verloren is gegaan, bestaan er voor de geschiedschrijving van dit gebouw enkele belangwekkende documenten: onder meer het genoemde document uit 1254, maar ook de stichtingsoorkonde van het kapittel door gravin Catharina uit 1469.

Uitzonderlijk zijn de passages over de Stevenskerk in de Gelderse kroniek (circa 1465) van Willem van Berchen, vicaris en later kanunnik van de kerk. Bij weinig middeleeuwse kerken in Nederland beschikken we over zo'n precieze bron. Van Berchen geeft zeer specifieke informatie over de bouwgeschiedenis, waarvan hij zelf getuige was. Zijn tekst kreeg terecht een prominente plek vooraan in het boek, met foto's van de relevante originele folio's, een transcriptie van de Latijnse tekst en een Nederlandse vertaling. Het betoog van Van Berchen is opvallend eenduidig en vaak goed te verenigen met de resultaten die uit het bouwhistorisch en architectuurhistorisch onderzoek naar voren zijn gekomen.

Het is aannemelijk dat de in $\mathbf{1 2 5 4}$ begonnen kerk in 1272 in aanzienlijke mate voltooid was en in ieder geval kon worden gebruikt. Op 7 september 1272 namelijk wijdde wijbisschop Albertus Magnus - optredend namens de aartsbisschop van Keulen waar Nijmegen destijds onder viel - drie altaren in de kerk waaronder het hoofdaltaar. De bouwgeschiedenis van de kerk tot in de zestiende eeuw was er vervolgens een van steeds weer nieuwe planwijzigingen en uitbreidingen. Emmens beschrijft er zeven: na (1) het basilicale dertiende-eeuwse kerkgebouw volgde de bouw van (2) de westtoren rond 1300 . Rond 1350 startte onder Reinoud III van Gelre de bouw van (3) een nieuwe oostpartij met dwarsschip, gevolgd door (4) de gedeeltelijke herbouw en uitbreiding van het schip (tussen circa 1390 en 1410) in de vorm van een hallenkerk. Na het gereedkomen hiervan werd besloten het zestig jaar oude koor te vervangen door (5) een nieuw omgangskoor met zij- en straalkapellen. Opvallend zijn de tweezijdig gesloten straalkapellen. Op 29 november 1429 brandde de kerktoren uit. De werkzaamheden aan het koor kwamen op een lager pitje te staan om eerst (6) een nieuwe toren te bouwen. Uiteindelijk zou de koorlantaarn van het hoogkoor zelfs niet meer gerealiseerd worden, zodat ook het koor de karakteristiek van een hallenkerk kreeg. Eind vijftiende eeuw begon de bouw van (7) een fors van zijbeuken voorzien transept op de plaats van het oude transept en de oostelijke travee van het schip. Ook dit project bleek te ambitieus. Net als het koor bleef het transept zonder de geplande lichtbeuk. Aan de uitvoering van het plan voor een nieuw schip werd helemaal niet meer begonnen. Met de Reformatie kwam een einde aan de architectonische ambities voor de Stevenskerk.

De bouwgeschiedenis die Emmens voorstelt is geen fundamenteel nieuwe, maar bevat wel talrijke verfijningen en correcties op die van Van Agt uit 1969. Zo weet hij niet alleen helderder de bouwfases, maar ook een aantal bouwcampagnes te onderscheiden. Onderzoek van Soenthgerat naar de steenhouwersmerken en van Den Hartog naar de bouwsculptuur (zie verderop) en niet in de laatste plaats de studie van Ronald Glaudemans naar de instandhoudingsgeschiedenis (in het bijzonder na de verwoestingen van de Tweede Wereldoorlog) leveren belangrijk aanvullend en contextueel materiaal.

Interessant is de passage die Emmens wijdt aan de eerste, in 1429 verwoeste toren van de kerk en de vergelijkende zoektocht naar nog bestaande kerktorens. Cruciaal daarin is de beschrijving van Willem van Berchen. Emmens kiest in zijn schematische reconstructie voor een toren waarvan de vier gevels de vorm van een gedecoreerde puntgevel hebben met daarop een vierzijdige spits van ruitvormige dakschilden en met op iedere hoek een klein hoektorentje, zoals de Patroklidom in Soest (Westfalen). De hoektorentjes zijn de interpretatie van 'cornu' bij Van Berchen. Maar de betekenis van dit woord in deze context is ongewis. Het is de vraag of Van Berchen inderdaad dergelijke hoektorentjes bedoelde of dat hij hiermee duidde op de gedecoreerde puntgevelvlakken. In het laatste geval zou de toren vooral gelijkenis hebben vertoond met die van de Apostelenkerk in Keulen, die Emmens overigens ook noemt. Het kapittel (en met name de deken) van deze kerk genoot tot aan de Reformatie de vruchten van de Nijmeegse parochie. De macht van het Apostelenstift blijkt meermaals uit de overgeleverde documenten en het is aannemelijk dat het ook invloed had op de architectonische keuzes voor de Stevenskerk.

Zeer welkom zijn de twee substantiële hoofdstukken over de bouwsculptuur, niet alleen ten behoeve van de bouwgeschiedenis, maar ook vanwege het beeldhouwwerk zelf, waarvan een deel van zeer hoog niveau is. Door verwering, godsdienststrijd, oorlog en restauratie is veel beeldhouwwerk verloren gegaan, vooral in het westelijk deel van de kerk. Er is echter voldoende oorspronkelijk materiaal over om de ontwikkeling van de decoratie in de loop van de eeuwen te volgen. Den Hartog laat zien dat de bouwsculptuur van de Stevenskerk aanvankelijk veel overeenkomsten vertoont met die elders in het Gelderse en Nederrijnse gebied. Dat geldt met name voor de dertiende-eeuwse knop- en knolkapitelen en de vroegvijftiende-eeuwse bladkranskapitelen met schotelachtige dekplaten in de kooromgang. Bij het transept - en speciaal het zeer fraaie zuidportaal met voorhal op 3/6-grondslag - voe- 
ren de relaties ook dieper in het Heilige Roomse Rijk. De detaillering van deze sculptuur uit de late vijftiende en vroege zestiende eeuw is van uitzonderlijke kwaliteit. Bij de bouwsculptuur van het transept komen vanaf het tweede kwart van de zestiende eeuw door de renaissance geïnspireerde vormen voor, maar ze bereiken lang niet de kwaliteit van het vroegere werk.

Het welkome intermezzo over het graf van Catharina van Bourbon maakt nieuwsgierig naar wat nu de rol van Gelderse graven en hertogen is geweest in de geschiedenis van de Stevenskerk. Nijmegen was als een van de hoofdsteden van Gelre in concurrentie met Arnhem, Roermond en Zutphen. Op welke manier maakten de machthebbers gebruik van de representatieve kracht van de kerkelijke bouwkunst? Hoe verhielden zich het Keulse Apostelenstift, de Gelderse graaf (later hertog) en de steeds zelfbewustere stedelijke elite in dit opzicht tot elkaar?

Wezenlijk voor het beeld van de middeleeuwse kerk is de veelkleurige afwerking. Paul le Blanc presenteert de muur- en gewelfschilderingen die - vaak fragmentarisch en/of sterk gerestaureerd - zijn overgeleverd. Deze dateren uit de periode 1450-1580. Vooral iconografisch zijn ze bijzonder, zoals de schildering met de heilige Ontkommer. Een opmerkelijke ontdekking tijdens de laatste restauratie was dat de afbeelding van een stad in een vensterdagkant in de zuidelijke zijbeuk de verdorven stad Babylon voorstelt, mogelijk als onderdeel van een Laatste Oordeel-iconografie.

Lezing van dit kloeke werk vraagt veel concentratie. Sommige auteurs duiken direct diep de materie in en dat maakt hun hoofdstukken minder toegankelijk. De lezer zou bijzonder geholpen zijn geweest met een al- gemene introductie op het kerkgebouw: een beschrijving en analyse op hoofdlijnen aan de hand van een aantal goede overzichtsfoto's (die worden node gemist), een plattegrond en doorsneden waarin de uitgebreide bouwfasering is aangegeven. Zowel een nummering van illustraties als verwijzingen ernaar in de tekst ontbreken. Hierdoor moet de lezer soms erg lang - en soms tevergeefs - zoeken of een gewenste afbeelding in het boek voorkomt. Het notenapparaat is beperkt gehouden, vooral in de reeks hoofdstukken over de middeleeuwse bouwgeschiedenis. Voor een boek dat zich ook richt op een breed publiek, is dat wellicht begrijpelijk. Voor de wetenschappelijk geïnteresseerden betekent het dat men soms op de niet-gepubliceerde bouwhistorische onderzoeken van Karel Emmens en, voor de zestiende eeuw, Jörg Soentgerath moet terugvallen.

Genoemde tekortkomingen lijken het gevolg van de spagaat tussen de wens om een boek voor een breed publiek te schrijven en de ambitie om een wetenschappelijke studie te publiceren. Adequate illustratieverwijzingen zouden het boek ook juist voor een algemeen publiek toegankelijker hebben gemaakt. En een aantal extra pagina's eindnoten zou bij deze dikke pil weinig hebben uitgemaakt. Dat alles laat echter onverlet dat deze nieuwe monografie over de Stevenskerk een belangrijke aanwinst is. Dat geldt in het bijzonder, maar zeker niet alleen, voor de middeleeuwse architectuur- en kunstgeschiedenis. Daarmee wordt het Nijmeegse karakter van het boek ruim overstegen.

JEROEN WESTERMAN 